406

NOTES AND NEWS

\title{
Socio-Economic Survey for Southern Rhodesia
}

A population and budget survey of the Southern Rhodesia African urban population, the first census of this kind to be carried out in Central Africa, was launched in April I957 and is expected to be completed in three years. African enumerators will be employed on the survey, after an intensive course of training under the Statistical Office. The census is expected to yield information which will be of great importance for government planning and development policy.

\section{Institute for Social Studies at Léopoldville}

THE first Institute for Social Studies was opened in Léopoldville in October 1956. After the first eliminating examination 18 students were admitted and it was hoped to admit further students after a second examination. In this school both white and African students will be trained in social science so that they may eventually work in the different social centres which are being opened in various parts of the Belgian Congo and especially in the large urban centres.

\section{University of Natal: Swaziland Research Project}

THE problem of labour stabilization for the development of Swaziland economy is the subject of a research project to be undertaken by the Institute for Social Research of the University of Natal.

New enterprises, mostly irrigation and forestry schemes, have been started and depend for their development on a steady supply of stable Swazi labour. New economic developments may also help to bring about a more even distribution of the population and so relieve pressure in present areas of high density.

The study will require about two years of active field work in Swaziland, some of it in close consultation and cooperation with Government administrative staff and other experts. In order to determine population trends, field work will have to include the collection of a certain amount of demographic data on a sampling basis, in addition to the normal analysis of the social structure. A thorough study of the indigenous concepts regarding land rights and usage, animal husbandry, and of the potential economic resources of land, stock and people, will have to be made. The African population is more homogeneous, and its traditional organization, culminating in a strong chieftainship, better preserved than in most other tribal areas in Southern Africa. The Swazi are a proud and colourful people, deeply and critically aware of the many problems challenging them at this vital stage in their development. It is not unlikely that this study, if successful, may lead to further research projects in Swaziland. 